\title{
The association of sports and physical recreation with life satisfaction in a community sample of people with spinal cord injuries
}

\author{
Tomasz Tasiemski ${ }^{\mathrm{a}, *}$, Paul Kennedy ${ }^{\mathrm{b}}$, Brian Patrick Gardner ${ }^{\mathrm{c}}$ and Nicola Taylor ${ }^{\mathrm{c}}$ \\ ${ }^{a}$ Institute of Rehabilitation, University School of Physical Education, Pozna ń, Poland \\ ${ }^{\mathrm{b}}$ Isis Education Centre, Oxford, UK \\ ${ }^{\mathrm{c}}$ National Spinal Injuries Centre, Stoke Mandeville Hospital, Aylesbury, UK
}

\begin{abstract}
The purpose of this study is to assess satisfaction with life domains in people with spinal cord injuries (SCI) and investigate whether participation in sports and physical recreation is associated with life satisfaction in SCI. 1,748 randomly selected participants with SCI who fulfilled the criteria: SCI at level C5 or below, wheelchair dependent; aged 18-50 at the time of injury; at least 1 year post-injury, were approached to take part in this study. Completed replies were received from 985 individuals with SCI (198 women, 798 men). The measures used included the Sports Participation Questionnaire, the Life Satisfaction Questionnaire and the Hospital Anxiety and Depression Scale. The numbers of hours participating in sports decreased significantly after injury. There was a greater decrease in numbers participating in team sports in comparison to the decrease seen in numbers participating in individual sports. The highest level of satisfaction existed within social domains such as: family life and contacts with friends. The lowest level of satisfaction was found in regard to the participant's sexual life and vocational situation. Higher satisfaction with life in general was demonstrated in respondents with SCI involved in sports or physical recreation compared to those not participating in physical activities.
\end{abstract}

Keywords: Spinal cord injury, life satisfaction, sports, physical recreation

\section{Introduction}

The quality of life (QOL) of people with spinal cord injuries (SCI) has been studied extensively. Researchers have presented mixed results regarding perceived global QOL in SCI partly due to the use of variable measurements and sample sizes. However, generally, satisfaction with life in SCI has been reported as high. Weitzenkamp and colleagues found that $78 \%$ of the subjects with SCI evaluated their QOL as good or

*Address for correspondence: Tomasz Tasiemski, PhD, Institute of Rehabilitation, University School of Physical Education, ul. Królowej Jadwigi 27/39, 61-871 Poznań, Poland. Tel.: +48 61835 51 62; Fax: +48 6183300 39; E-mail: tashma@poczta.onet.pl. excellent [44]. When Gerhart [16] interviewed individuals with SCI, asking them to rate their lives directly, twenty-one $(60 \%)$ rated it as good or excellent but, of those who rated their QOL as excellent, none had a complete injury. The QOL of people with SCI has been found to be lower than that of the general population. Dunnum [11] found this to be the case and Westgren and Levi's study found the QOL of examined patients with SCI was significantly lower in comparison to a normative population [45]. Likewise, Fuhrer and colleagues [13] reported lower life satisfaction in SCI than reported previously for the general population.

Some investigators did not find differences in life satisfaction between persons with SCI and the general population or even suggested slightly higher satisfac- 
tion with life amongst subjects with SCI. Lundqvist and colleagues [26] studied overall QOL of patients with SCI and found that their QOL perceptions did not differ from those of a control population sample. Siosteen and colleagues [37] presented similar findings. Cushman and Hassett [7] examined functional changes and perceptions regarding QOL in SCI. Those people with SCI who survived 10 and 15 years post-injury rated their QOL as equal to, or somewhat better than, that of their peers. Looking at overall life satisfaction as a measure of QOL, Post et al. [33] found that social functioning, marital status and psychological functioning were significant predictors of life satisfaction of people with SCI.

Research has compared the QOL of people with SCI to the QOL of other disabled groups. Kemp and Krause [23] reported on life satisfaction of persons with SCI in comparison to Polio and non-disabled subjects. They found that the group with SCI was lower than the other groups in any of the investigated areas of life. Clayton and Chubon [6] found that participants with SCI perceived their QOL to be high but lower than non-disabled students and some other disabled groups (cardiac patients and rheumatoid arthritis).

\section{Physical activity and QOL}

Physical recreation and sports has been shown to be correlated with an increase in QOL for people with and without disabilities. This relationship was advocated more than half a century ago, when Sir Ludwig Guttmann first introduced a sports and exercise program as part of rehabilitation following SCI, believing in its positive influence on physical, psychological and social rehabilitation $[17,18]$. Since that time, many healthcare professionals and researchers have also assumed that the greater the sports activity and fitness level achieved through a rehabilitation program, the more positive the impact on biological and physiological characteristics of people with disabilities. This assumption has been demonstrated in other health-related areas. Rojas [35] assigned HIV-1 positive individuals to an exercise or control group (no exercise). After a 16-week exercise intervention, the exercise group experienced a "significant improvement in cardiopulmonary fitness and health related quality of life". Sutherland et al. [40] assessed the effects of an exercise program on health related quality of life (HRQL) of individuals with multiple sclerosis. It was found that the individuals who followed the 10-week exercise program had more energy and vigor and also better social and sexual functioning, less bodily pain and fatigue than the control group who did not follow a program. A further study, which lends support to the link between sports activity and fitness levels and positive impact on biological and physiological characteristics, was that conducted by Courneya et al. [8]. Exercise during the hospitalization of individuals undergoing bone marrow transplants was shown to be correlated with QOL indices, including physical well-being, psychological well-being, depression, anxiety and days hospitalized [8].

Physical recreation and sports help to prevent disease, promote health and maintain functional independence, essential for people with and without disabilities [20]. However, physical activity has been linked to other, more subjective, psychological benefits. Such psychological benefit, gained by partaking in physical activity, highlights the distinction that must be made between the observable and subjective benefits of physical activity. Diener [10] states that subjective measures of health are more strongly related to life satisfaction than objective indexes of health, supporting the psychological construct that QOL is a cognitive judgment. Rajeski and Mihalko [34] found that correlations between measures of fitness and HRQL were weaker than correlations between performance-based measures of dysfunction and HRQL. Certainly, for people with SCI, there are many cases where people report high QOL despite significant functional limitations.

Activity theorists state that a source of satisfaction arises not from the endpoint or outcome of an activity but the process of pursuing the activity i.e. behavior (e.g. for older people with SCI this statement has particular resonance). Others have suggested that physical activity has a positive effect on self-efficacy [22] (e.g. in a randomized clinical trial physical activity was found to have positive effects on perceived physical function in older women [27]). Diener [10] reported that self-esteem is a strong predictor and other research has suggested that self-esteem and positive feeling states may mediate the effect that physical activity has on life satisfaction. Research looking at physical activity in older adults found that physical activity increased the older adults' energy and overall level of positive affect. Valliant and colleagues [42] found that athletes with disabilities (people in wheelchairs, blind people and people with cerebral palsy) had significantly higher self-esteem, exhibited greater life satisfaction and happiness, were more externalized and attained more education than non-athletes with disabilities.

In the early stages of rehabilitation, patients may benefit from exercise training programs, which may result 
in observable changes e.g. resistance or strength training program, rather than programs focusing on changes in aerobic capacity. It was proposed from Rajeski's study, mentioned earlier, that performance-based measures are more observable than measure of fitness, thus acting as a positive reinforcer [34]. This highlights the importance of patients' perception of improvement. Thus, positive feedback from intermittent assessments in performance are crucial to patients sticking to the program and changing their QOL. The positive benefits of social interaction were seen in a study by Labronici and colleagues [24]. They found that adults with physical disabilities, who played basketball or swam, presented substantial improvement regarding their relationships with people and in everyday activities, leading to better social integration. The importance of mediating variables such as promoting and shaping selfschema of competence in performing physical tasks, as well as being physically fit, together with positive reinforcement which enhances self-efficacy perceptions, generates feelings of control and ultimately increases satisfaction with that area of life [34].

There is a lack of research specifically about how exercise and sports recreation can improve the QOL of a person with a SCI and the few studies, which have investigated this relationship, have failed to prove a positive correlation. Manns and Chad [27] attempted to determine the relationship between fitness or physical activity and subjective QOL (measured by the Quality of Life Profile: Physical and Sensory Disabilities Version) in 38 persons with SCI. There was no relationship between the subjective QOL scores and fitness and physical activity in either persons with tetraplegia or paraplegia. Similarly, Cushman and Hassett [7] did not find any significant relationship between general QOL and involvement in exercise or other recreational activities in a sample of 43 individuals with SCI. However, these two studies used small sample sizes. This is a problem faced by many studies as there are usually not many subjects with SCI available for such studies, since involvement in physical activities after SCI decreases significantly in comparison to the preinjury period [41]. In addition to this, a clear definition as to whether someone with SCI is involved in sports/physical recreation, or not, remains problematic.

\section{Study aim and assumption}

The purpose of this study is to assess satisfaction with life domains in people with SCI and investigate whether participation in sports and physical recreation is associated with life satisfaction in SCI. No clear suggestion has been made about which of the existing QOL instruments would meet the needs of a uniform QOL measure $[1,4,9,12,19]$. However, taking into consideration the typical QOL instrument criteria, i.e. reliability, validity, responsiveness, interpretability, practicality and cross-country applicability [19], it has been found that the Life Satisfaction Questionnaire [15] is a satisfactory QOL measure and previous research has used this measure with people with disabilities such as patients with strokes [43], multiple sclerosis [5,25] and other physical disabilities including SCI [31]. Based upon previous research looking at the effects of exercise and sports participation on QOL $[34,35,40]$, it is expected that the QOL will be greater in those people who participated more frequently in sports and physical recreation.

\section{The pilot study}

Prior to this study, a pilot project regarding sport, recreation and employment following SCI had been carried out [41]. Forty-five subjects, all patients of the National Spinal Injuries Centre (NSIC) at Stoke Mandeville Hospital, Aylesbury, UK, completed a postal questionnaire. Among the 45 subjects, $47 \%$ participated in physical activities ( $20 \%$ in sports, $27 \%$ in physical recreation), $33 \%$ were employed (29\% full-time) and $18.5 \%$ had undergone further education at the time of the survey. Participation in sports, as well as employment status, decreased after injury, usually as a result of poor access to sport and work facilities. Only $4 \%$ of the patients started to practice physical activity after the accident, whilst $42 \%$ stopped. The association of sports and physical recreation with life satisfaction in this small sample has not been studied.

\section{Methods}

\subsection{Setting}

The data for this study was gathered in three spinal injuries centers in the United Kingdom: the NSIC, Stoke Mandeville Hospital, Aylesbury; the Princess Royal Spinal Injuries Unit (PRSIU), Northern General Hospital, Sheffield; and the Queen Elizabeth National Spinal Injuries Unit (QENSIU), South Glasgow University Hospital, Glasgow. 
This study is part of a larger research project looking into QOL, sports and recreation involvement, educational achievements and employment status in SCI. This study was approved by the Aylesbury Vale Health Authority Ethics Committee, the North Sheffield Research Ethics Committee and the South Glasgow Ethics Committee.

\subsection{Study participants and procedure}

Potential study participants were identified from available outpatient records according to criteria for inclusion in the study: SCI at level C5 or below, wheelchair dependent (ASIA grade: A, B or C) [28], aged between 18 and 50 at the time of injury, injured at least 1 year prior to the study, admitted to the spinal unit within 6 months of injury and resident in the UK. The sample consisted of 1,748 outpatients with SCI who met the study criteria (985 from NSIC, 606 from PRSIU and 157 from QENSIU). These individuals were sent a package which included a letter of explanation, a questionnaire booklet and a stamped addressed envelope. To maximise the response rate, 4-6 weeks after the original questionnaire was sent out, a reminder package was posted to all of the participants who did not respond to the first letter. The final study group consisted of those people with SCI who completed questionnaires mailed to them. Completed replies were received from 985 (58.7\% of the whole sample) individuals with SCI. The response rate was $64.4 \%$ for NSIC, $51.0 \%$ for PRSIU and $53.7 \%$ for QENSIU. Of those who did not respond, 34 individuals could not be located because of a change of address and 29 people were found to have died.

\subsection{Measures}

\subsubsection{The sports participation questionnaire}

This questionnaire consisted of 26-items, covering demographic characteristics and sports participation pre- and post-injury [41]. Demographic characteristics included age, marital status, injury characteristics (such as cause, level of injury, use of wheelchair), education, employment status, and housing status. Most questions, except age, were answered using fixed responses. Participants were asked how many hours a week they participated in sport pre- and post-injury $(0$, $<1,1<3,3<6$ and $6+$ hours), in a multiplechoice fixed-response format. In addition, they were asked whether their predominant sport was individual or team based, and how many years they had practised the sport. They were also asked whether they were able to practice their favorite sport post-injury and, if not, whether this was due to their disability, or the lack of opportunity. Participants were asked how difficult it was to access information regarding sport for people with disabilities after injury (complete and regular access, difficult access or no access). In order to identify athlete status, participants were asked to state their highest level of sporting achievement in terms of international (Paralympic/world championships), national and regional/local attainment. Finally, participants were asked to identify all the reasons why they engaged in sporting activity post-injury ( 8 items) and all the reasons which made it difficult for them to engage in sporting activity post-injury ( 9 items). Out of all data gathered by this questionnaire only selected information, important for this report, were used for this study.

To define clearly the degree to which a participant was involved in sport, to allow clear analysis, and due to almost equal dispersal of percentages within four categories for sports active participants, sports variables were merged into three categories:

(1) Those who practised physical activities '3-5 hours/week' and ' 6 hours or more',

(2) Those who practised physical activities '1-2 hours/week' and 'less than 1 hour/week' were classified as participating in physical recreation and

(3) Other respondents were classified as not active in sports.

\subsection{The life satisfaction questionnaire (LSQ)}

To assess participants' life satisfaction the LSQ was used [14]. The LSQ contains one question about global life satisfaction (life as a whole) and eight questions about domain-specific life satisfaction: self-care ability, leisure situation, vocational situation, financial situation, sexual life, partnership relation, family life, contacts with friends and acquaintances. All nine questions can be answered on a six-point scale ( $1=$ very dissatisfied up to $6=$ very satisfied). Global life satisfaction was reported on the basis of a single item (life as a whole). Relationship between life satisfaction and different variables was reported in regard to general (i.e. total) life satisfaction, computed by adding the score of all nine items and dividing it by nine. While searching for predictors of life satisfaction, a mean score of all nine items is a more reliable (reproducible) vari- 
able than a single item measure (life as a whole) [33]. The LSQ scale was, following previous research, dichotomized into $1-4 / 5-6$ in order to distinguish those who were dissatisfied, from those who were satisfied [5, $14,15,25,32,33]$.

\subsubsection{The Hospital Anxiety and Depression Scale (HADS)}

The participants' mood was evaluated using the HADS [47]. This 14-item self-report questionnaire measures anxiety (HADS-A) and depression (HADSD). Seven items relate to each dimension, requiring answers on a 4-point scale e.g. from 0 (not at all) to 3 (very often indeed), and to each point a reply is assigned, which represents possible feelings in the past week. The total anxiety score and total depression score were calculated by adding all seven item scores within each subscale. The measure has demonstrated good internal consistency with Cronbach alpha values ranging from 0.68 to 0.93 for HADS-A, and from 0.67 to 0.90 for HADS-D [3]. Test-retest reliability has also been demonstrated to be good (0.85) [30]. The validity of cut-off scores has also been investigated with certain populations. In their literature review, Bjelland and colleagues [3] report that the optimal balance between sensitivity and specificity for 'caseness' is achieved with a cut-off of $8+$ on each subscale. Zigmond and Snaith [47] recommend that raw scores of between 8 and 10 identify mild cases, 11-15 moderate cases, and 16 or above - severe cases, for each dimension. Concurrent validity has been evaluated mainly using the Beck Depression Inventory [2] and the State-Trait Anxiety Inventory [39]. Bjelland and colleagues [3] report a range of correlations with other measures from 0.49 to 0.83 . The HADS has been previously used with the SCI population [37].

\subsection{Analysis}

Descriptive statistics were used for presentation of the results. To find the differences between life satisfaction scores and sports participation, the univariate analysis of variance (ANOVA) was performed. Multiple comparison Bonferroni t-tests, which take into account the fact that multiple comparisons are being made and adjusts the significance level accordingly, thus reducing the risk of alpha inflation, were performed. Logistic regression analysis was used to determine the strength of association between life satisfaction and independent variables, in order to identify the best predictors of life satisfaction. Statistical analysis was performed using SPSS version 11.0.

\section{Results}

\subsection{Demographic characteristics}

A total of 985 persons with SCI participated in this study. The mean age of all the subjects at the time of injury was 28.6 years (range: $18-50, \mathrm{SD}=9.20$ ) and the mean age at the time of the questionnaire was 48.1 years (range: $20-87, \mathrm{SD}=12.74$ ). At the time of this study, participants had been injured on average for 19.5 years, with a range from 2 to 58 years $(\mathrm{SD}=12.74)$. $34.8 \%$ subjects had tetraplegia and $65.2 \%$ had paraplegia. All of the participants were wheelchair dependent i.e. the wheelchair was, for them, the main source of locomotion for daily activities and sports: $94.1 \%$ used a wheelchair all the time, and 5.9\% mainly for outdoor mobility and long distances. Within a 24 hour period, participants required personal assistance or care for an average of 6.19 hours ( $S D=8.20)$. Housing was usually either fully adapted to the needs of a wheelchair user, or accessible, enabling independent access in and out of the house $(92.9 \%)$. $60.9 \%$ of respondents had higher education (college and above) and 39.1\% had school education (primary or secondary). Employment rate (full-time or part-time) amongst participants was $36.1 \%$. The detailed demographic characteristics are presented in Table 1.

\subsection{Participation in sports}

About half of the investigated people with SCI (46.7\%) were involved in some kind of sport or physical activity at the time of the questionnaire. The most commonly practised sports post-injury were swimming, archery, weight-training, basketball, table tennis, and the most common reason for doing it was improvement of physical condition.

Figure 1 shows the number of hours participants practised sport before their injury, and at the time they completed the questionnaire.

A Chi-squared test found a significant difference $\left(\chi^{2}=104.682, d f=4, p<0.001\right)$ between the number of hours spent practising sport. Figure 1 shows that the number of hours was significantly less after injury. The largest difference after injury was found for those who had previously been involved in a lot of sport (6 hours or more).

A Chi-squared test found a significant difference $\left(\chi^{2}=44.721, d f=1, p<0.001\right)$ between those who participated in individual and team sports, before and after their injury, indicating that fewer participants 


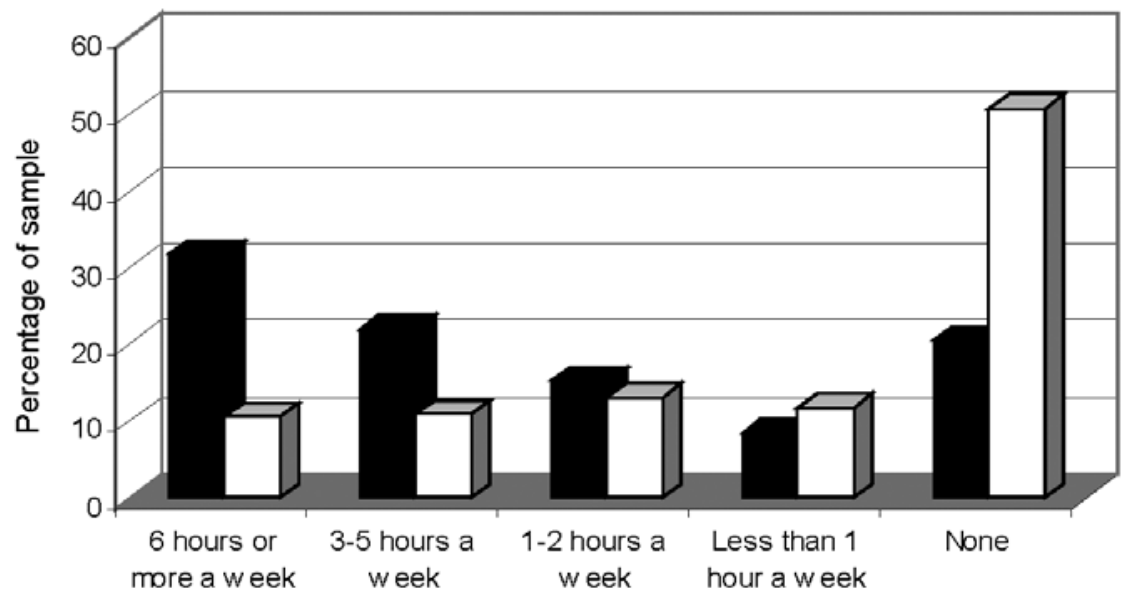

Before Injury $\square$ After Injury

Fig. 1. Number of hours practicing sport before and after SCI.

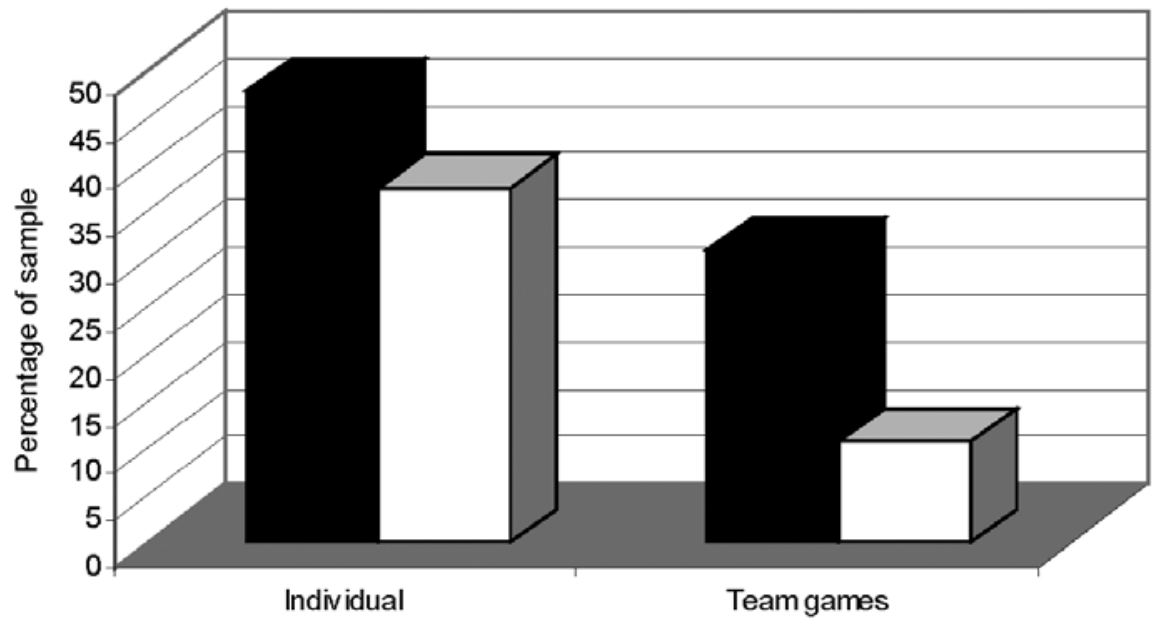

Before Injury 口After Injury

Fig. 2. Percentage of sample practicing individual or team sports before and after SCI.

participated in individual and team sports after injury. Figure 2 shows that the difference in the percentage of participants taking part in team sports, pre- and postinjury, was greater than the corresponding difference for those taking part in individual sports.

Half of the sample had not practised their favourite sport since their injury because of their disability, and over half the sample $(57.7 \%)$ stated that information regarding sport for the disabled was difficult to access, requiring effort on the part of the interested person.

Figure 3 shows the reasons, encountered by the participants, which make it difficult to undertake or continue sports activity after their injury.

Figure 4 shows the reasons why participants decided to undertake or continue sports activity after injury.

Amongst 134 participants with sports-related injuries, before injury $4.5 \%$ were not active in sports,
$13.5 \%$ were involved in physical recreation and $82.0 \%$ were involved in sports. The corresponding figures for these participants after injury were: $44.4 \%, 24.4 \%$ and $31.3 \%$ respectively. The differences were not significant.

\subsection{Life satisfaction and its domains}

The mean score for participants with SCI $(n=985)$ happiness (life as a whole) was 4.22 , i.e. between 'rather satisfying' and 'satisfying'. The highest level of satisfaction existed within two social domains: family life (4.76) and contacts with friends and acquaintances (4.49). In contrast, the lowest level of satisfaction was found in regard to the participants' sexual life (2.76). Apart from these three domain-specific areas of life satisfaction, only two other aspects were 


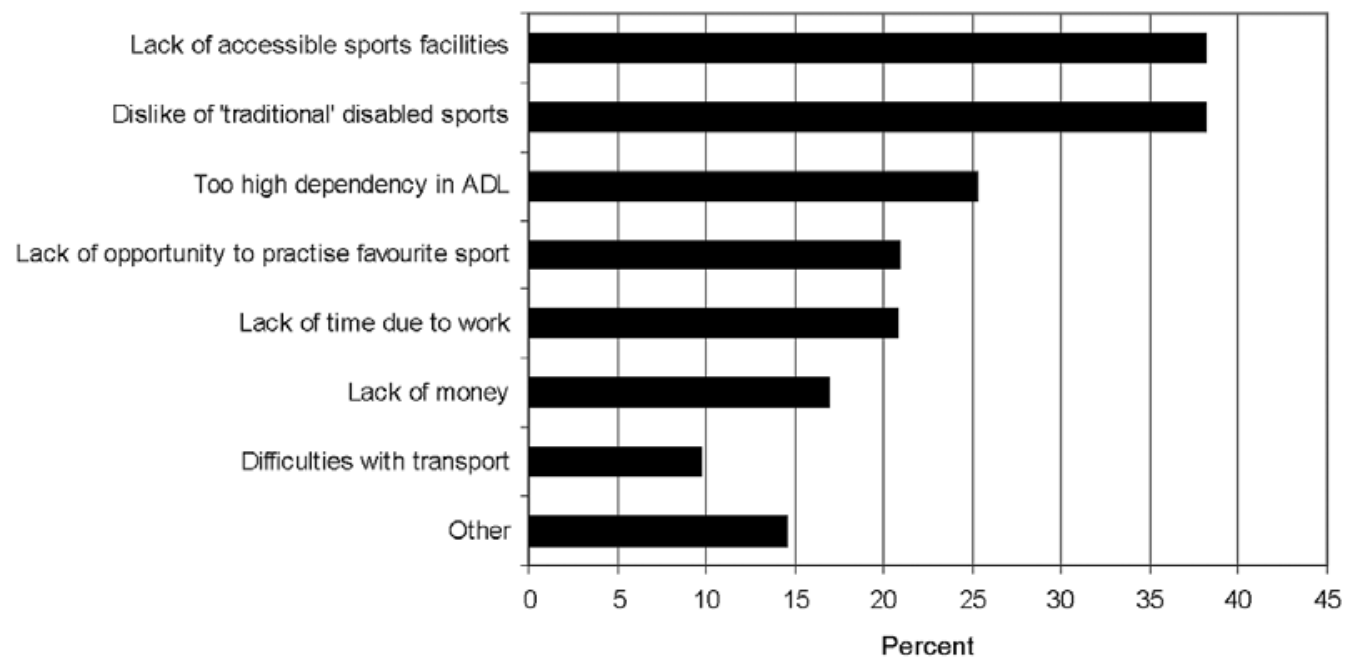

Fig. 3. Reasons encountered by the participants making it difficult to undertake or continue sports activity after SCI.

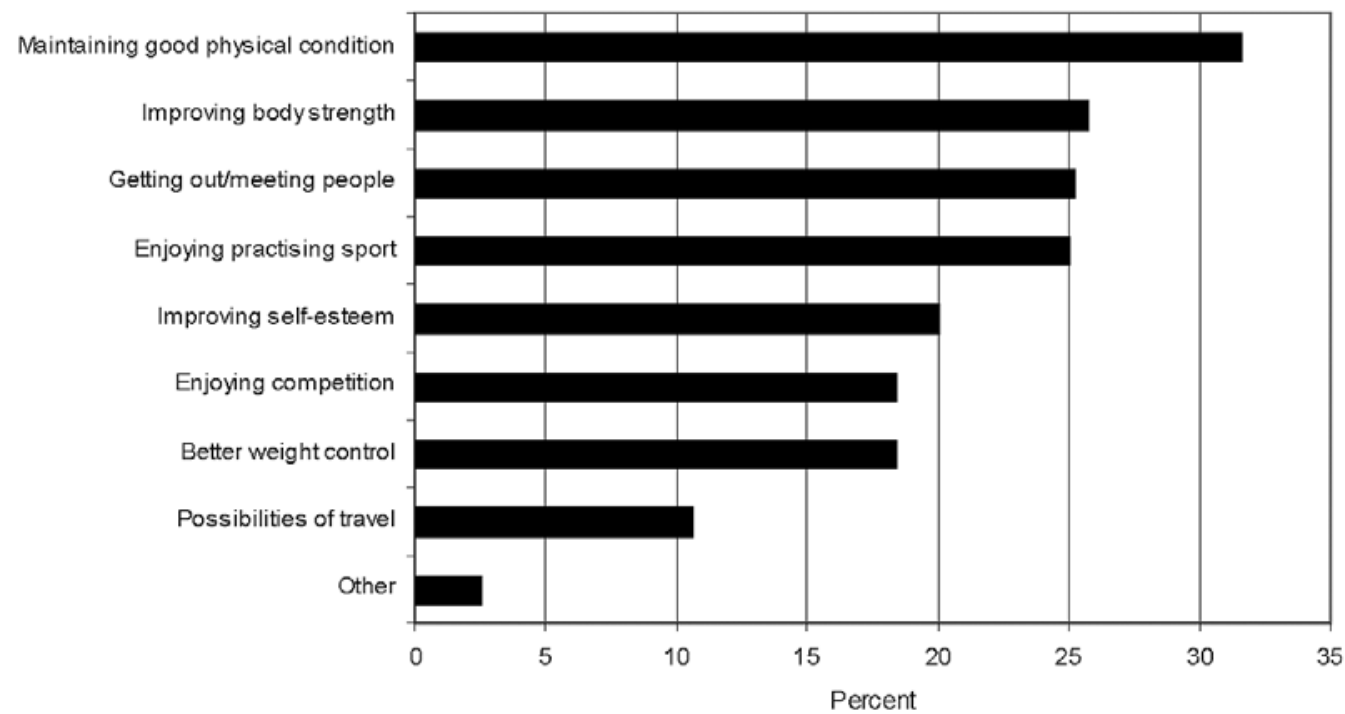

Fig. 4. Reasons given by participants why they decided to undertake or continue sports activity after SCI.

rated above 'rather satisfying': the ability to manage self-care (4.01) and partnership relations (4.07). All the other items of the LSQ such as: leisure situation, vocational situation and financial situation were scored between 'rather dissatisfying' and 'rather satisfying'. The total mean score for life satisfaction amongst all subjects with SCI was 3.94 (range: 1-6, $S D=0.99$ ). A proportion of participants did not respond to questions about partnership relations $(9.2 \%)$, vocational situation $(7.8 \%)$ and sexual life $(7.4 \%)$. The percentage of missing data in other questions was much lower: life as a whole (3.6\%), ability to manage selfcare $(3.7 \%)$, leisure situation $(3.7 \%)$, financial situation
(4.1\%), family life (4.7\%) and contacts with friends and acquaintances $(3.1 \%)$. Division into satisfied and dissatisfied groups showed $67.4 \%$ of respondents were satisfied with family life, followed by contact with friends $(56.6 \%)$, partnership relations $(54.9 \%)$, self-care ability (49.6\%), leisure (40.0\%), vocational situation (35.5\%), financial situation (35.4\%) and sexual life (21.5\%).

\subsection{Life satisfaction and sports participation}

The results of the univariate ANOVA identified significant differences between life satisfaction and sports participation. Apart from partnership relations, all the 
Table 1

Demographic characteristics of 985 respondents with SCI at the time of the study

\begin{tabular}{|c|c|}
\hline & $\begin{array}{l}\text { SCI participants } \\
(n=985)\end{array}$ \\
\hline \multicolumn{2}{|l|}{ Gender } \\
\hline Male & $798(81.0 \%)$ \\
\hline Female & $187(19.0 \%)$ \\
\hline \multicolumn{2}{|l|}{ Marital status } \\
\hline Single & $309(31.4 \%)$ \\
\hline Married/living with partner & $520(52.8 \%)$ \\
\hline Divorced/separated & $128(13.0 \%)$ \\
\hline Widowed & $28(2.8 \%)$ \\
\hline \multicolumn{2}{|l|}{ Level of injury/ASIA grade } \\
\hline Tetraplegia A & $216(21.9 \%)$ \\
\hline Tetraplegia B & $65(6.6 \%)$ \\
\hline Tetraplegia C & $61(6.2 \%)$ \\
\hline Paraplegia A & $535(54.3 \%)$ \\
\hline Paraplegia B & $38(3.9 \%)$ \\
\hline Paraplegia C & $70(7.1 \%)$ \\
\hline \multicolumn{2}{|l|}{ Cause of injury } \\
\hline Road traffic accident & $489(49.7 \%)$ \\
\hline Fall & $172(17.5 \%)$ \\
\hline Sports accident & $134(13.5 \%)$ \\
\hline Nontraumatic & $25(2.5 \%)$ \\
\hline Assault & $12(1.2 \%)$ \\
\hline Unknown & $153(15.5 \%)$ \\
\hline \multicolumn{2}{|l|}{ Education } \\
\hline Primary & $21(2.2 \%)$ \\
\hline Secondary & $364(36.9 \%)$ \\
\hline College & $403(40.9 \%)$ \\
\hline University degree & $145(14.7 \%)$ \\
\hline Higher degree & $52(5.3 \%)$ \\
\hline \multicolumn{2}{|l|}{ Employment } \\
\hline Student & $35(3.6 \%)$ \\
\hline Employed full-time & $269(27.3 \%)$ \\
\hline Employed part-time & $87(8.8 \%)$ \\
\hline Homemaking/parenting & $55(5.6 \%)$ \\
\hline Unemployed & $451(45.7 \%)$ \\
\hline Retired & $88(8.9 \%)$ \\
\hline \multicolumn{2}{|l|}{ Place of living } \\
\hline City & $204(20.7 \%)$ \\
\hline Town & $419(42.5 \%)$ \\
\hline Village & $362(36.8 \%)$ \\
\hline
\end{tabular}

other aspects of the LSQ were related to participation in sports activities. Individuals with SCI not active in any kind of sports or physical recreation ('not active') had lower satisfaction with life as a whole $\left(\mathrm{F}_{(2,927)}=\right.$ $11.452, p<0.001)$ than those involved in sports ('sports') or physical recreation ('recreation'). Subjects with SCI 'not active' in sports also had lower satisfaction than two other groups ('sports' or 'recreation') with ability to manage self-care $\left(\mathrm{F}_{(2,926)}=39.737\right.$, $p<0.001)$, leisure situation $\left(\mathrm{F}_{(2,927)}=26.000\right.$, $p<0.001)$, vocational situation $\left(\mathrm{F}_{(2,887)}=11.977\right.$, $p<0.001)$ and sexual life $\left(F_{(2,893)}=13.698\right.$, $p<0.001)$. Participants with SCI, actively involved in 'sports', had higher satisfaction with financial situation $\left(F_{(2,922)}=6.661, p=0.001\right)$, contacts with friends and acquaintances $\left(F_{(2,930)}=6.882, p=0.001\right)$ and family life $\left(F_{(2,917)}=4.461, p=0.012\right)$ than 'not active' participants.

\subsection{General life satisfaction}

Significant differences were found between general (total) life satisfaction and participation in sports $\left(\mathrm{F}_{(2,820)}=29.381, p<0.001\right)$. Life satisfaction was correlated with those who had lower anxiety $(r=$ $-0.419, p<0.01)$ and depression scores $(r=-0.660$, $p<0.01)$.

Logistic regression analysis revealed that four out of the nine independent variables combine to significantly predict life satisfaction (Chi-squared $=225.923, p<$ 0.001). These were: $\operatorname{mood}($ Wald $=69.194, p<$ 0.001 ), marital status (Wald $=36.194, p<0.001$ ), loss of independence $($ Wald $=12.944, p<0.001)$ and sports participation $($ Wald $=4.901, p=0.027$ ).

\section{Discussion}

This research explored satisfaction with life domains in people with SCI and the factors predicting and associated with life satisfaction and SCI. Generally, the finding confirmed those of previous studies, however, it elaborates on the specific contribution of participation in sports and physical recreation.

\subsection{Participation in sport}

The number of hours participating in sports was found to be significantly less after injury. Half the sample did not participate in sports after their injury, compared to $20 \%$ before the injury. However, data concerning sports participation pre-injury could have been susceptible to inflation due it is retrospective nature, as participants had been injured, on average, for more than 8 years. Results suggested that the numbers participating in team sports decreased considerably more after injury, than those participating in individual sports.

Wu and Williams [46] concluded in their study that there is lack of research identifying the difficulties and reasons why people with SCI do not participate in sport activities and how they can be encouraged to participate in those activities. The reasons why sports participation decreases after SCI are not explicit but could be linked to the answers participants gave as to why 
Table 2

Univariate analysis of variance between life satisfaction scores of 985 SCI persons and categorical variables

\begin{tabular}{|c|c|c|c|c|}
\hline $\begin{array}{l}\text { Life Satisfaction } \\
\text { Questionnaire }\end{array}$ & $\begin{array}{c}\text { Sports } \\
\text { participation }\end{array}$ & $\begin{array}{c}\text { Marital } \\
\text { status }\end{array}$ & $\begin{array}{c}\text { Level } \\
\text { of education }\end{array}$ & $\begin{array}{c}\text { Employment } \\
\text { status }\end{array}$ \\
\hline Life as a whole & $F_{(2,927)}=11.452^{*}$ & $F_{(3,946)}=12.223^{*}$ & $F_{(4,922)}=0.742$ & $F_{(5,918)}=5.229^{*}$ \\
\hline Ability to manage self-care & $F_{(2,926)}=39.737^{*}$ & $F_{(3,945)}=1.059$ & $F_{(4,921)}=0.279$ & $F_{(5,917)}=7.541^{*}$ \\
\hline Leisure situation & $F_{(2,927)}=26.000^{*}$ & $F_{(3,945)}=2.730$ & $F_{(4,920)}=0.900$ & $F_{(5,918)}=1.522$ \\
\hline Vocational situation & $F_{(2,887)}=11.977^{*}$ & $F_{(3,904)}=1.985$ & $F_{(4,879)}=3.683^{*}$ & $F_{(5,887)}=23.104 *$ \\
\hline Financial situation & $F_{(2,922)}=6.661^{*}$ & $F_{(3,941)}=5.665^{*}$ & $F_{(4,917)}=1.654$ & $F_{(5,914)}=13.297 *$ \\
\hline Sexual life & $F_{(2,893)}=13.698^{*}$ & $F_{(3,908)}=14.919^{*}$ & $F_{(4,886)}=2.325 *$ & $F_{(5,882)}=4.805^{*}$ \\
\hline Partnership relations & $F_{(2,875)}=2.254$ & $F_{(3,890)}=220.250 *$ & $F_{(4,868)}=0.512$ & $F_{(5,864)}=3.556^{*}$ \\
\hline Family life & $F_{(2,917)}=4.461^{*}$ & $F_{(3,935)}=33.783^{*}$ & $F_{(4,910)}=0.955$ & $F_{(5,907)}=0.673$ \\
\hline Contacts with friends and acquaintances & $F_{(2,930)}=6.882^{*}$ & $F_{(3,950)}=3.881^{*}$ & $F_{(4,925)}=0.527$ & $F_{(5,922)}=1.848$ \\
\hline LSQ Total & $F_{(2,820)}=29.381^{*}$ & $F_{(3,832)}=37.992^{*}$ & $F_{(4,813)}=0.325$ & $F_{(5,807)}=8.908^{*}$ \\
\hline
\end{tabular}

$* p<0.1$.

they found it difficult to continue participating in sports. In answer to this question, the most common reason, given by $38 \%$ of participants, was due to dislike of traditional "disabled sports". It seems that this could be easily overcome in the rehabilitation process. Nowadays, almost every year, there are new sports available for people with SCI. Scientific and technological progress which take place all over the world, especially in the manufacturing of specialized sports equipment, as well as the aspiration of people with SCI for practicing even extreme sports, mean that the last barriers between sports for people with disabilities and the ablebodied are being removed. The fact that people with SCI are able today to pilot gliders and aircrafts, climb up mountains or attend cross-country hand-biking races do not require any comments. This knowledge should be popularized among all of those people with SCI who look for something other than traditional "disabled sports", such us archery or table tennis. Also, 38\% of participants stated that a lack of accessible facilities made it difficult to undertake or continue sports after injury, and about $30 \%$ of the sample stated that they were too highly dependent in activities of daily living (ADL). To intervene in the first area, pressure should be put on local authorities to ensure access to public sports facilities. In many countries, there are spinal injuries associations or other non-governmental organizations gathering people with SCI which may influence political as well as economical decisions being made regarding a barrier-free environment for people with disabilities. Too high dependency in ADL is a serious problem which limits participation in sports, but there are sports available even for people with high tetraplegia which do not require high efficiency in ADL, such us bowling, bocce, swimming or quad-rugby (defence players). On the other hand, in some countries, very high social support given to people with SCI (e.g. personal assistance not justified in all cases or too many home adaptations not always needed) may negatively affect a person's independence in ADL. A special approach should be taken when working with individuals who enjoyed sports pre-injury but no longer participate given the "lack of opportunity to practice their favourite sport" (25\%). If someone's favourite sport before injury was e.g. football it could be very difficult to find a satisfactory equivalent after the injury. However, many people with SCI may not be aware that there are a number of new sports for people with SCI which are a good equivalent for regular sports like hand-cycling (cycling), mono-skiing (alpine skiing), water-skiing or cross-country skiing (special cages attached to skis), quad-rugby (rugby), ice hockey (special seat attached to hockey skates) and many others. Physical or occupational therapists working with people with SCI should look for such equivalents or try to discover new sports that would satisfy appeal to their patients. There seems to be no limit to human invention in this area.

The most common reason given by participants as to why they decided to undertake or continue sports activity after injury was maintenance of physical condition $(32 \%)$ and improving upper body strength (26\%). More subjective reasons, such as getting out and meeting people and the enjoyment of practising sport, were given by around a quarter of the sample. However, it must be noted that $55 \%$ of the sample did not answer the question. A reason for this could be that participants who were not active in sports felt that this question was not applicable and, therefore, did not provide an answer. In the $\mathrm{Wu}$ and Williams study [46], the reasons for participation in sports after SCI were similar to this study but given in a different order. Their participants with SCI rated "fun" the highest, followed by "fitness", "health", "competition" and "social". The "rehabilitation" aspect was not a principle for them, but it should 
be noted that the sample consisted of either very fit or fairly fit subjects.

\subsection{Life satisfaction and its domains}

This study found that the mean score for subjects with SCI happiness (life as a whole) was 4.2 , i.e. between 'rather satisfying' and 'satisfying'. Apart from the global life satisfaction, the LSQ revealed areas of life in which participants with SCI were more or less satisfied. In this SCI sample the highest level of satisfaction existed within social domains such as: family life (mean score 4.8), contacts with friends and acquaintances (4.5) and partnership relations (4.1). The lowest level of satisfaction was found in regard to the participant's sexual life (2.8) and vocational situation (3.7).

Despite cultural differences, the final results of this investigation are very similar to findings of Post and colleagues [32] who used identical measures. In order to compare the results of Post's study with the results of this study, only ASIA grade A or B tetraplegics $(n=65)$ and paraplegics $(n=89)$ were extracted from the Post et al. study [32]. In their SCI sample, the mean score for happiness was 4.3. Subjects with SCI had slightly higher global life satisfaction than other disabled people (4.0) but lower than the normative population (4.7) [29]. Post's [32] findings, like the current study, found that the highest satisfaction existed in the same three social domains: contacts with friends and acquaintances (5.0), family life (4.9) and partnership relations (4.7). Similarly, the lowest mean scores were in regard to sexual life (3.1) and vocational situation (3.8).

Other studies, such as that conducted by Fugl-Meyer and colleagues [15], studied life satisfaction amongst disabled people with diagnosis of bodily impairment, finding that the highest satisfaction was in regard to partnership relations (4.9), family life (4.8) and contacts with friends and acquaintances (4.7). Lundmark and Branholm [25] studied life satisfaction amongst 30 patients with multiple sclerosis. The highest satisfaction existed in family life (satisfied: $93 \%$ v $67 \%$ in this study), contacts with friends (satisfied: $71 \%$ v $57 \%$ in this study) and partnership relations (satisfied: $57 \% \mathrm{v}$ $55 \%$ in study) and the lowest satisfaction existed within vocational situation (2.9) and financial situation (3.6). The results of this study were compared to 64 people with multiple sclerosis in Branholm and Erhardsson's study [5]. People with SCI had higher satisfaction with self-care (satisfied: $20 \%$ v 50\% in this study), leisure (satisfied: $27 \%$ v $40 \%$ in this study) and vocational situation (satisfied: $24 \%$ v $36 \%$ in this study). Overall, satisfaction with specific life satisfaction domains in this current SCI sample was lower than earlier reported for SCI population or other disabled people [15,25,32].

Comparing findings of this study with the general population in the Netherlands [32], people with SCI had lower satisfaction in all but one life satisfaction domain (family life: $4.8 \mathrm{v} 4.4$ ). When compared to a Swedish population [14], subjects with SCI had lower satisfaction with all life domains e.g. family life (satisfied: $83 \%$ v $67 \%$ in this study), contacts with friends (satisfied: $60 \%$ v $57 \%$ in this study) and partnership relations (satisfied: $82 \%$ v $55 \%$ in this study).

Different studies have almost consistently reported specific life domains that are of great importance and high satisfaction for people with SCI. More often than not contacts with family, friends and partnership relations were described as most important and most satisfying for persons with SCI. Contrary, within the areas of minor satisfaction in SCI, sexual life and employment have usually been listed. In Fuhrer's study [13], participants with SCI gave highest satisfaction ratings to the domains of 'family relationships', 'spiritual life' and 'daily living tasks'. Associated with the lowest satisfaction were 'money matters', 'sex life' and 'employment'. In an investigation conducted by Smith [38], 'family', 'friends', and 'home' were listed as most satisfied life areas, and 'bowels/bladder', 'mobility', 'sex' as least satisfied.

\subsection{Predictors of life satisfaction}

As the calculation of general life satisfaction improves the reliability (homogeneity) of the total LSQ score, this report regarding predictors of life satisfaction is based on the Post and associates approach [33]. The findings of this study revealed that higher satisfaction with life in general was demonstrated in respondents with SCI involved in sports or physical recreation compared to those not participating in physical activities. While using LSQ there is a distinction between reporting general life satisfaction on the basis of the single item (life as a whole), or giving the mean score of all nine items (general life satisfaction). In this study, participation in physical activities was also positively related to 7 out of 8 life satisfaction domains (Table 2). Whilst it is believed that an active sporting life-style is positively related to general life satisfaction, the few studies that have previously investigated participation in sports and exercise have failed to es- 
tablish such a relationship between that and QOL. The lack of any relationship may be due to the relatively small sample sizes used. However, one of the studies did find that those who exercised regularly made fewer changes in their daily routine due to fatigue. It could be said that exercise could thus affect mood or physically based phenomena, such as fatigue, a highly subjective concept which has been said to be mediated by these factors [7]. This theory is substantiated by a study by Schwartz [36] who explored the relationship of exercise on fatigue and QOL in 31 women with breast cancer. The results suggested that exercise may have affected QOL, but this was mediated by the effects of exercise on fatigue.

\subsection{Study limitations}

This study did have a number of limitations, which may have effected the results. The cross-sectional design of this study inherently produces less reliable results, since the sample was only investigated at one time period. Only half the identified sample participated in the study. This introduces the possibility that the sample was biased and thus reduces the ability to generalize the results to other people with SCI. No analyses regarding the impact of level of injury or length of time post-injury on sports' participation were conducted, however, previous research showed that there is correlation between these two factors and sports participation post-SCI. The only explanation for this is that this study focused mainly on the association between sports' participation and life satisfaction in SCI, and analyses of too many other factors could influence the clarity of the paper. Also, no analyses regarding differentiation of complete versus incomplete injuries was done but, regardless of completeness of injury, the wheelchair was the main source of daily locomotion for all participants with SCI. This somehow "equalizes" study subjects in their abilities to participate in sports post-SCI.

\section{Conclusion}

Despite serious physical, social and psychological challenges as a result of SCI, participants in this study were rather satisfied with their life in general. Despite a reported decrease in time spent participating in sports, and difficulties in partaking in such activities, almost half $(47 \%)$ of the investigated people with SCI were involved in sports or physical recreation after injury and their life satisfaction was significantly higher than among those not active in sports. The best predictors of life satisfaction were found to be mood, marital status, loss of independence and sports participation (anxiety and depression, marital status and employment status were also associated with general life satisfaction.)

Steps should be taken to increase awareness amongst the SCI population about the possibilities of engaging in new and traditional sports and both the psychological and physical benefits of doing so. Factors should be examined that may be associated with increased sports participation such as financial status, individually tailored programs and positive feedback. Further research is needed to examine the significance of an active sporting life-style and its influence on everyday life and the perceived QOL in the SCI population. Further research is also required to identify and clarify differences in QOL of SCI population between different nations.

\section{Acknowledgements}

This study was funded by the European Commission, Research Directorate General, Brussels, Belgium (Contract No. QLGA-CT-2000-51115). The authors gratefully acknowledge David Ash and Jonathan Hasler for identifying study participants and collecting data in two geographical UK regions (Scotland and East Midlands), and to all those who took part in the study.

\section{References}

[1] J.L. Alexander and E.P. Willems, Quality of life: some measurement requirements, Archives of Physical Medicine \& Rehabilitation 62 (1981), 261-265.

[2] A.T. Beck, R.A. Steer and G.K. Brown, The Beck Depression Inventory - II. Manual. The Psychological Corporation, Harcourt Brace \& Co: San Antonio, 1996.

[3] I. Bjelland, A.A. Dahl, T. Tangen Haug and D. Neckelmann, The validity of the Hospital Anxiety and Depression Scale: An updated literature review, Journal of Psychosomatic Research 52 (2002), 69-77.

[4] C.J. Bulpitt, Quality of life as an outcome measure, Postgraduate Medical Journal 73 (1997), 613-616.

[5] I.B. Branholm and M. Erhardsson, On life satisfaction and activity preferences in subjects with multiple sclerosis: a comparative study, Scandinavian Journal of Occupational Therapy 1 (1994), 17-23.

[6] K.S. Clayton and R.A. Chubon, Factors associated with the quality of life of long-term spinal cord injured persons, Archives of Physical Medicine and Rehabilitation 75 (1994), 633-638.

[7] L.A. Cushman and J. Hassett, Spinal cord injury: 10 and 15 years after, Paraplegia 30 (1992), 690-696. 
[8] K.S. Courneya, M.R. Keats and R.A. Turner, Physical exercise and quality of life in cancer patients following high dose chemotherapy and autologous bone marrow transplantation, Psycho-Oncology 9(2) (2000), 127-136.

[9] M. Dijkers, Quality of life after spinal cord injury: a meta analysis of the effects of disablement components, Spinal Cord 35 (1997), 829-840.

[10] E. Diener, Psychological bulletin \{Psychol-Bull\} 1984 May, VOL: 95(3), P: 542-75, Refs: 241, ISSN: 0033-2909.

[11] L. Dunnum, Life satisfaction and spinal cord injury: the patient perspective, Journal of Neuroscience Nursing 22 (1999), 43-47.

[12] R.L. Evans, R.D. Hendricks, R.T. Connis, J.K. Haselkorn, K.R. Ries and T.E. Mennet, Quality of life after spinal cord injury: a literature critique and meta-analysis (1983-1992), Journal of the American Paraplegia Society 17 (1994), 60-66.

[13] M.J. Fuhrer, D.H. Rintala, K.A. Hart, R. Clearman and M.E. Young, Relationship of life satisfaction to impairment, disability, and handicap among persons with spinal cord injury living in the community, Archives of Physical Medicine and Rehabilitation 73 (1992), 552-557.

[14] A.R. Fugl-Meyer, I.B. Branholm and K.S. Fugl-Meyer, Happiness and domain-specific life satisfaction in adult northern Swedes, Clinical Rehabilitation 5 (1991), 25-35.

[15] A.R. Fugl-Meyer, M. Eklund and K.S. Fugl-Meyer, Vocational rehabilitation in northern Sweden. III Aspects of life satisfaction, Scandinavian Journal of Rehabilitation Medicine $\mathbf{2 3}$ (1991), 83-87.

[16] K.A. Gerhart, Spinal cord injury outcomes in a populationbased sample, Journal of Trauma-Injury Infection and Critical Care 31 (1991), 1529-1535.

[17] L. Guttmann, Sport and the spinal cord sufferer, Nursing Mirror and Midwives Journal 141 (1975), 64-65.

[18] L. Guttmann, Significance of sport in rehabilitation of spinal paraplegics and tetraplegics, Journal of the American Medical Association 236 (1976), 195-197.

[19] P. Hallin, M. Sullivan and M. Kreuter, Spinal cord injury and quality of life measures: a review of instrument psychometric quality, Spinal Cord 38 (2000), 509-523.

[20] N.S. Hansen, M. Forchheimer, D.G. Tate and G. Luera, Relationships among community reintegration, coping strategies, and life satisfaction in a sample of persons with spinal cord injury, Topics in Spinal Cord Injury Rehabilitation 4 (1998), 56-72.

[21] G.W. Heath and P.H. Fetham, Physical activity among persons with disabilities-a public health perspective, Exercise and Sport Sciences Reviews 25 (1997), 195-234.

[22] J.A. Katula and E. McAuley, The mirror does not lie: Acute exercise and self-efficacy, International Journal of Behavioral Medicine 8(4) (2001), 319-326.

[23] B.J. Kemp and J.S. Krause, Depression and life satisfaction among people ageing with post-polio and spinal cord injury, Disability and Rehabilitation 21 (1999), 241-249.

[24] R.H.D. Labronici, M.C.B. Cunha, A. Oliveira and A.A. Gabbai, Sport as integration factor of the physically handicapped in our society, Arquivos de Neuro-Psiquiatria 50(4) (2000), 1092-1099.

[25] P. Lundmark and I.B. Branholm, Relationship between occupation and life satisfaction in people with multiple sclerosis, Disability and Rehabilitation 18 (1996), 449-453.

[26] C. Lundqvist, A Siosteen, C. Blomstrand, B. Lind and M. Sullivan, Spinal cord injuries. Clinical, functional, and emotional status, Spine 16 (1991), 78-83.
[27] P.J. Manns and K.E. Chad, Determining the relation between quality of life, handicap, fitness, and physical activity for persons with spinal cord injury, Archives of Physical Medicine and Rehabilitation 80 (1999), 1566-1571.

[28] F.M. Maynard Jr, M.B. Bracken MB, G. Creasey, J.F. Ditunno Jr, W.H. Donovan, T.B. Ducker et al., International standards for neurological and functional classification of spinal cord injury, Spinal Cord 35(5) (1997), 266-274.

[29] S.L. Milhako, Strength training in older women: Does selfefficacy immediate improvements in physical function? Dissertation Abstracts International Section A: Humanities \& Social Sciences 58 (1997), 2134.

[30] J.M. Quintana, A. Padierna, C. Esteban, I. Arostegui, A. Bilbao and I. Ruiz, Evaluation of the psychometric characteristics of the Spanish version of the Hospital Anxiety and Depression Scale, Acta Psychiatrica Scandinavica 107 (2003), 216-221.

[31] P. Mittler, Quality of life and services for people with disabilities, Bulletin of the British Psychological Society 37 (1984), 218-225.

[32] M.W.M. Post, A.J. Van Dijk, F.W.A. Van Asbeck and A.J.P. Schrijvers, Life satisfaction of persons with spinal cord injury compared to a population group, Scandinavian Journal of Rehabilitation Medicine 30 (1998), 23-30.

[33] M.W.M. Post, L.P. De witte, F.W.A. Van Asbeck, A.J. Van Dijk and A.J.P. Schrijvers, Predictors of health-status and life satisfaction in spinal cord injury, Archives of Physical Medicine and Rehabilitation 79 (1998), 395-401.

[34] W.J. Rajeski and S.L. Mihalko, Physical activity and quality of life in older adults, Journals of Gerentology: Series A: Biological sciences and medical sciences, special issue: Nutrition, physical activity, and quality of life in older adults 56(11), 23-35.

[35] R. Rojas, W. Schlicht and M. Hautzinger, Effects of exercise training on Quality of life, psychological well-being, immune status, and cardiopulmonary fitness in an HIV-1 positive population, Journal of Sport and Exercise Psychology 25(4) (2003), 440-455.

[36] A.L. Schwartz, Fatigue mediates the effects of exercise on quality of life, Quality of Life Research: An international journal of quality of life aspects of treatments, care \& rehabilitation 8(6) (1999), 529-538.

[37] A. Siosteen, C. Lundqvist, C. Blomstrand, L. Sullivan and M. Sullivan, The quality of life of three functional spinal cord injury subgroups in a Swedish community, Paraplegia 28 (1990), 476-488.

[38] M. Smith, Making the difference - efficacy of specialist versus non-specialist management of spinal cord injury, Spinal Injuries Association, London, 1999, 113-118.

[39] C.D. Spielberger, P.C. Gorsuch and R.E. Lushene, Manual of the State Trait Anxiety Inventory, Palo Alto, CA: Consulting Psychologists Press, 1970.

[40] G.A. Sutherland, M.B. Anderson and M.A. Stoove, Can aerobic exercise training affect health-related quality of life for people with multiple sclerosis? Journal of Sport \& Exercise Psychology 23(2) (2001), 122-135.

[41] T. Tasiemski, E. Bergstrom, G. Savic and B.P. Gardner, Sports, recreation and employment following spinal cord injury - a pilot study, Spinal Cord 38 (2000), 173-184.

[42] P.M. Valliant, I. Bezzubyk, L. Daley and M.E. Asu, Psychological impact of sport on disabled atheletes, Psychological Reports 56(3) (1985), 923-929.

[43] M. Viitanen, K.S. Fugl-Meyer, B. Bernspang and A.R. FuglMeyer, Life satisfaction in long-term survivors after stroke, 
Scandinavian Journal of Rehabilitation Medicine 20 (1988), $17-24$.

[44] D.A. Weitzenkamp, K.A. Gerhart, S.W. Charlifue, G.G. Whiteneck, C.A. Glass and P. Kennedy, Ranking the criteria for assessing quality of life after disability: evidence for priority shifting among long-term spinal cord injury survivors, British Journal of Health Psychology 5 (2000), 57-69.

[45] N. Westgren and R. Levi, Quality of life and traumatic spinal cord injury, Archives of Physical Medicine and Rehabilitation 79 (1998), 1433-1439.

[46] S.K. Wu and T. Williams, Factors influencing sport participation among athletes with spinal cord injury, Med Sci Sport Exc 33(2) (2001), 177-182.

[47] A. Zigmund and R.P. Smith, The hospital anxiety and depression scale, Acta Psychiatrica Scandinavica 67 (1983), 361370. 